\title{
Correction to: Principles for a Responsible Integration of Mindfulness in Individual Therapy
}

\author{
Johannes Michalak ${ }^{1,2} \cdot$ Catherine Crane $^{3} \cdot$ Christopher K. Germer $^{4}$ • Eluned Gold ${ }^{5}$ - Thomas Heidenreich ${ }^{6}$. \\ Johannes Mander ${ }^{7} \cdot$ Petra Meibert $^{2} \cdot$ Zindel V. Segal $^{8}$
}

Published online: 12 November 2019

(C) Springer Science+Business Media, LLC, part of Springer Nature 2019

\section{Correction to: Mindfulness (2019) 10:799-811 https://doi.org/10.1007/s12671-019-01142-6}

The original version of this article was revised twice due to the following changes:

(1) The article "Principles for a Responsible Integration of Mindfulness in Individual Therapy", written by Johannes Michalak, Catherine Crane, Christopher K. Germer, Eluned Gold, Thomas Heidenreich, Johannes Mander, Petra Meibert, and Zindel V. Segal, was originally published electronically on the publisher's internet portal (currently SpringerLink) on 29 April 2019 without open access.

With the author(s)' decision to opt for Open Choice the copyright of the article changed on July 2019 to () The Author(s) 2019 and the article is forthwith distributed under the terms of the Creative Commons Attribution 4.0 International License (http://creativecommons.org/ licenses/by/4.0/), which permits use, duplication, adaptation, distribution and reproduction in any medium or format, as long as you give appropriate credit to the original author(s) and the source, provide a link to the Creative Commons license and indicate if changes were made.

(2) The article "Principles for a Responsible Integration of Mindfulness in Individual Therapy", written by Johannes Michalak, Catherine Crane, Christopher K. Germer, Eluned Gold, Thomas Heidenreich, Johannes Mander, Petra Meibert, and Zindel V. Segal, was originally published electronically on the publisher's internet portal (currently SpringerLink) on 29 April 2019 with open access.

With the author(s)' decision to step back from Open Choice, the copyright of the article changed on October 2019 to (C) Springer Science+Business Media, LLC, part of Springer Nature 2019 and the article is forthwith distributed under the terms of copyright.

The original article has been corrected.

Publisher's Note Springer Nature remains neutral with regard to jurisdictional claims in published maps and institutional affiliations.
The online version of the original article can be found at https://doi.org/10. 1007/s12671-019-01142-6

Johannes Michalak

johannes.michalak@uni-wh.de

1 Deparment of Psychology and Psychotherapy, Witten/Herdecke University, Alfred-Herrhausen-Straße 50, D-58448 Witten, Germany

2 Achtsamkeitsinstitut Ruhr, Essen, Germany

3 University of Oxford, Oxford, UK
Harvard Medical School, Boston, USA

5 Bangor University, Bangor, UK

6 Esslingen University of Applied Sciences, Esslingen am Neckar, Germany

University of Heidelberg, Heidelberg, Germany

8 University of Toronto Scarborough, Toronto, Canada 